\title{
Low Circulation of Zika Virus, Cambodia, 2007-2016
}

\section{Veasna Duong, Sivuth Ong, Rithea Leang, Rekol Huy, Sowath Ly, Ugo Mounier, Teyputita Ou, Saraden In, Borin Peng, Sreymom Ken, Philippe Buchy, Arnaud Tarantola, Paul F. Horwood, Philippe Dussart}

We describe a retrospective study on circulation of Zika virus in Cambodia during 2007-2016 among patients with dengue-like symptoms and Aedes aegypti mosquitoes. Our findings suggest that Zika virus in Cambodia belongs to the Asia genotype, is endemic, has low prevalence, and has had low-level impact on public health.

$\mathrm{Z}$ ika virus (family Flaviviridae, genus Flavivirus) is an arthropodborne virus mainly transmitted by the Aedes mosquito. Zika virus was first isolated in 1947 in Africa from rhesus macaques, and human illness was first recognized in Uganda in 1964 (1). This virus is known to cause various and nonspecific symptoms, such as fever, rash, arthralgia, headache, and conjunctivitis. In the second half of the 20th century, although the virus was detected in Africa and in Malaysia, only serologic evidence of Zika virus was reported in India, Thailand, Pakistan, Indonesia, Vietnam, and the Philippines (2). The first well-documented outbreak of Zika virus occurred in 2007 in Yap State, part of the Federated States of Micronesia (3), was followed by further outbreaks in the region (e.g., French Polynesia, New Caledonia, and Easter Island) in 2014 (2). Zika virus was detected in mainland South America in March 2015 in Brazil (4), subsequently spreading in South and Central America and most of the Caribbean over a short period (2). Before recent introduction and outbreaks of Zika virus in Singapore and Thailand (5), only sporadic autochthonous cases have been reported in Southeast Asia, whereas travel-associated cases from Zika-endemic countries have been detected in the United States, Europe, Southeast Asia, and Australia (2).

Zika virus infections have been associated recently with evidence of microcephaly related to transmission from mother to fetus during the first trimester of pregnancy (6). Moreover, other neurologic syndromes and nonvector

Author affiliations: Institut Pasteur, Phnom Penh, Cambodia

(V. Duong, S. Ong, S. Ly, U. Mounier, T. Ou, S. In, B. Peng,

S. Ken, A. Tarantola, P.F. Horwood, P. Dussart); National Center

for Parasitology, Entomology, and Malaria Control, Phnom Penh

(R. Leang, R. Huy); GlaxoSmithKline Vaccines Research and

Development, Singapore (P. Buchy)

DOI: http://dx.doi.org/10.3201/eid2302.161432 modes of Zika virus transmission, including congenital, perinatal, and sexual, have been also described (7).

Cambodia's National Dengue Surveillance System is a pediatric hospital-based syndromic surveillance system of suspected dengue cases managed by the Ministry of Health's National Dengue Control Program (NDCP). Acute- and convalescent-phase samples from $\approx 5$ patients randomly selected from each of the 5 sentinel sites in the NDCP system are collected and tested each week at Institut Pasteur du Cambodge (IPC) to ensure virologic diagnosis and surveillance (8). The first case of Zika virus infection in Cambodia was diagnosed in a 3-year-old child through community surveillance of acute fevers conducted during 2006-2010 in parallel to the NDCP sentinel system (9).

\section{The Study}

We conducted a retrospective study by using samples in our biobank: 1) acute-phase serum and supernatant from NDCP collected during January 2007-July 2016; 2) acute- or convalescent-phase serum and supernatant samples collected by private clinics for dengue diagnosis during the same period; and 3) urine from dengue-negative patients and mosquito samples included in the DENFREE study conducted in Cambodia during 2012-2013 (online Technical Appendix 1, http://wwwnc.cdc.gov/EID/article/23/2/16-1432-Techapp1. pdf). The use of samples was approved by the National Ethics Committee for Health Research of Cambodia. We also tested 3,159 Ae. aegypti female mosquitoes negative for dengue infection by quantitative real-time reverse transcription PCR (qRT-PCR). In total, 2,400 serum samples and 173 supernatants from C6/36 cell cultures of serum from the dengue surveillance system, 270 urine samples from the DENFREE study, and 3,159 mosquitoes were tested for Zika virus by qRT-PCR (10). Positive results were confirmed by using conventional RT-PCR targeting the nonstructural protein 5 gene (11) and the Trioplex qRT-PCR kit (12). DNA products of conventional RT-PCR were sent for sequencing to a commercial sequencing facility (Macrogen, Inc., Seoul, South Korea). Serum samples were also tested for Zika virus IgM, dengue virus (DENV), and Japanese encephalitis virus (JEV) by using an in-house IgM capture ELISA (MACELISA) (13). The interval between the date of symptom onset and the date of sampling ranged from 0 to 26 days ( $n=$ 1,922; mean 4.13 days, $95 \%$ CI 1.66-6.6 days).

Five human serum samples were positive for Zika virus by qRT-PCR; these samples were collected in 2007 $(\mathrm{n}=1), 2008(\mathrm{n}=1), 2009(\mathrm{n}=2)$, and $2015(\mathrm{n}=1)$ 
(online Technical Appendix 2, http://wwwnc.cdc.gov/EID/ article/23/2/16-1432-Techapp2.xlsx). No other samples, including urine and mosquito samples, were positive. Among the 5 positive samples, 3 were also positive by conventional RT-PCR. Phylogenetic analysis of partial sequences of the nonstructural protein 5 gene from human samples (1 from 2008 and 2 from 2009) showed that all 3 strains belonged to the Asia genotype. Zika virus strain S1118214 (GenBank accession no. KX455424) isolated in 2008 clustered closest with strains from the outbreak in Micronesia (2007); 1 of the strains isolated in 2009, T0706225 (accession no. KX455425), clustered closest with outbreak or endemic strains from New Caledonia (2014), Thailand (2014), China (2016), Chile (2014), and French Polynesia (2013); and the other strain isolated from 2009, T1002464 (accession no. KX455426), clustered closest with the Cambodia strain previously isolated in 2010 (9) (Figure 1). These findings suggests that Zika virus strains in Cambodia are closely related
Figure 1. Phylogenetic tree of Zika virus partial nonstructural protein 5 gene of 3 strains detected from humans in Cambodia. The partial sequences of the nonstructural protein 5 gene (192$194 \mathrm{nt})$ generated from the PCR products obtained for each strain were analyzed and assembled by using CLC Main Workbench 5.5 package (CLC bio A/S, Aarhus, Denmark). MEGA6 (14) was used to perform multiple sequence alignment of Cambodia strains with Zika virus reference strains from Africa and Asia genotypes available in GenBank and phylogenetic analyses by using maximum-likelihood method using the general time reversible model with 1,000 bootstrap resampling. Spondweni virus (GenBank accession no. AF013406) was used to root the tree. Cambodia strains from this study are indicated by bold type and a black triangle, and the Cambodia strain isolated in 2010 is indicated by bold type and a white triangle. Scale bar indicates nucleotide substitutions per site.
KU365778 BeH819015 BRA15

67 KU312312 Z1106033 SUR15

59 KU501215 PRVABC59 PRI15 KU365777 BeH818995 BRA15 KU365780 BeH815744 BRA15 5 KU365779 BeH819966 BRA15 KU497555 Brazil-ZKV2015 BRA15 ${ }_{41}$ - KU527068 Natal RGN BRA15

KU647676 MTQ15 - KU321639 ZikaSPH2015 BRA15 - KU729217 BeH823339 BRA15

- KU729218 BeH828305 BRA15 KU501216 103344 GUA15

86 KU501217 8375 GUA15 KJ873161 NCL14

KJ873161 NCL14
KU681081 THA 14 KJ776791 H/PF/2013 PYF13 KJ873160 NCL14 KU509998 HTI14

KM078930 CHI2283714 CHL14 59 KM078929 CHI1805214 CHL14 - A KX455425_T0706225 KH09 KU744693 VE Ganxian CHN16 LF993678 PLCal ZV TH13 AKX455426_T1002464 KH09 ${ }_{90} \Delta \mathrm{JN} 860885$ FSS13025 KHM10 1 $\triangle$ KX455424_S1118214 KH PP08 EU545988 FSM07 KU681082 PHL 12

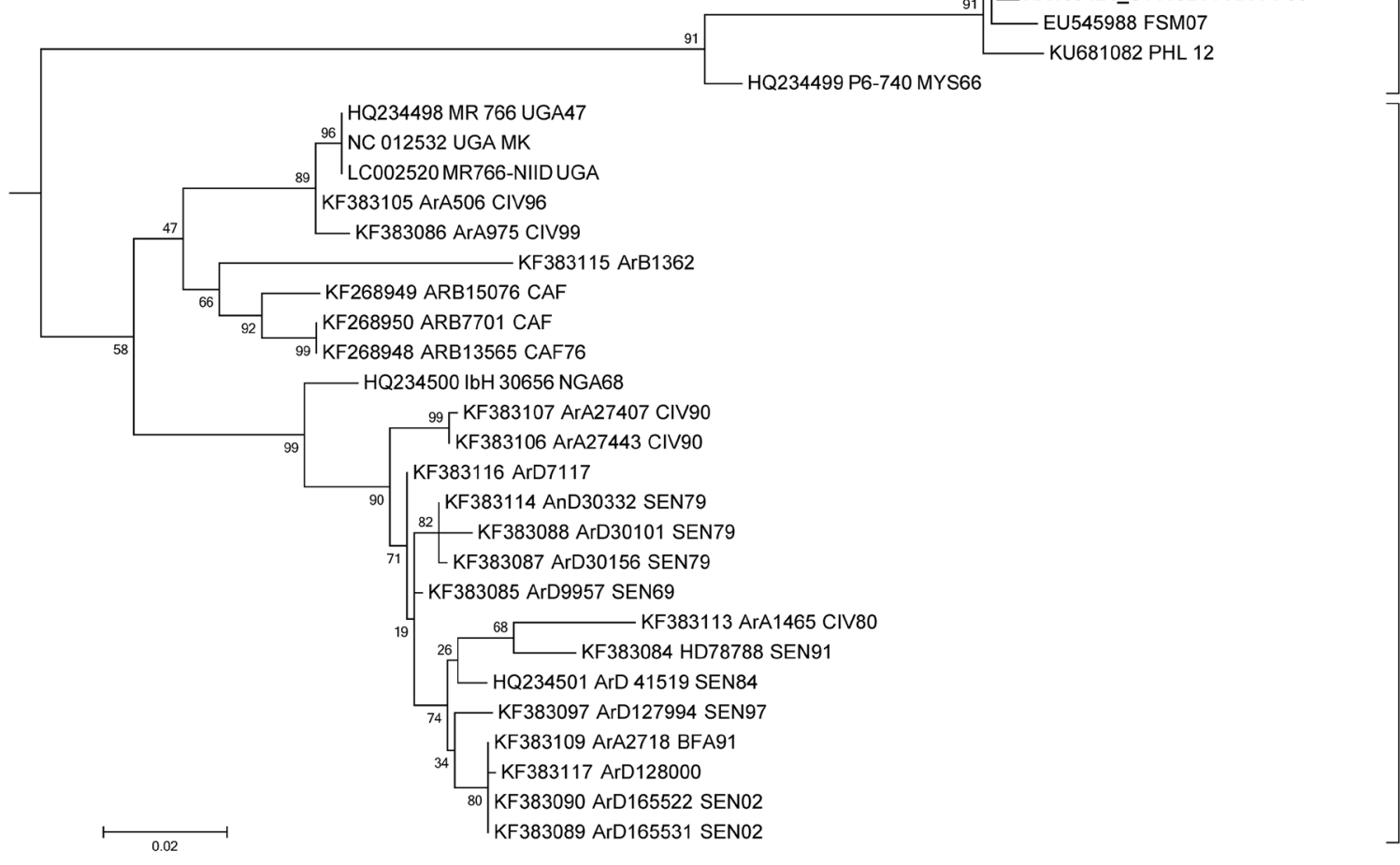

Asia genotype

Africa genotype 
to strains causing outbreaks in the Pacific and South America and to endemic strains circulating in Asia; however, longer sequences are needed to confirm this finding.

The serologic study of 1,992 acute-phase serum samples showed that 16 samples from $2007(\mathrm{n}=2), 2008(\mathrm{n}$ $=1), 2010(\mathrm{n}=2), 2012(\mathrm{n}=4)$, and $2015(\mathrm{n}=7)$ were positive for Zika virus IgM, with no cross-reactivity with DENV and JEV, suggesting a presumptive diagnosis of recent infection. The interpretation of the 1,976 remaining samples is distributed as follows: 146 recent DENV infections; 4 recent JEV infections; 743 recent flavivirus infections (defined by IgM detection for $\geq 2$ of 3 antigens tested [DENV, JEV, and Zika virus]); and 1,087 samples negative for antibodies for any of the 3 viruses tested.

The PCR- and IgM-positive Zika virus infections we detected came from 9 provinces in north, central, and south Cambodia (Figure 2). All 5 acute-phase samples that tested positive by RT-PCR were negative by MAC-ELISA. The convalescent-phase serum samples exhibited a pattern of recent flavivirus infection in 2 samples and recent Zika virus infection in 1 sample (online Technical Appendix 2). The confirmed case in 2015 was considered to be an autochthonous case because no history of recent travel to Zika-endemic areas was reported by the patient. During January-May 2016, all suspected dengue samples that tested negative for DENV were also tested for Zika virus; no cases were detected, either by serology or RT-PCR.
We show that Zika virus circulated across Cambodia during the past 10 years with low intensity and limited effect on public health. No clear explanation exists for the low detection of Zika virus by RT-PCR or by MAC-ELISA, but it might be attributable to 1) the low incidence of Zika virus, which usually causes mild disease compared with DENV, in Cambodia; 2) possible bias in the selection of viremic cases, which were mainly reported in hospitalized suspected dengue patients and therefore were more severe; 3) less than ideal timing of specimen collection for the detection of Zika virus, which has been shown to be transient and frequently low-titer and too early for detection of Zika virus IgM on acute-phase serum samples; or 4) the difficulty in interpreting MAC-ELISA results owing to the cross-reactivity of IgM between DENV and JEV, which are widely present in Cambodia.

\section{Conclusions}

The epidemiology of Zika virus is changing, and the risk for reintroduction in Cambodia is a real threat that should not be underestimated. Thailand, Vietnam, and Laos have reported cases since December 2015, and, local transmission has been observed recently in Singapore $(5,15)$. Ae. aegypti and Ae. albopictus mosquitoes are widespread throughout Cambodia. The risk for reemergence or reintroduction of Zika virus should be monitored by extending the existing surveillance program to ambulatory suspected

Figure 2. Geographic distribution of Zika virus in Cambodia. PCR- and IgM-positive cases were from 9 different provinces in north, central and south Cambodia. The 5 Zika virus-positive samples by quantitative real-time reverse transcription (qRTPCR) in this study were distributed as follows: the $2007(n=1)$ sample was received from Kampong Cham province, and the other cases from $2008(n=1), 2009(n=2)$, and 2015 $(n=1)$ were from the Phnom Penh area (red star). The first case of Zika virus infection previously reported in Cambodia by conventional RT-PCR was diagnosed in a patient from Kampong Speu province (9). The 16 additional serum samples found to be positive for Zika virus IgM were, from oldest to the most recent, from Phnom Penh (2007, $\mathrm{n}=1 ; 2008, \mathrm{n}=$ $1 ; 2010, n=2)$; Battambang (2007, $\mathrm{n}=1 ; 2012, \mathrm{n}=1)$; Takeo (2012, $\mathrm{n}$ =1); Kampong Speu (2012, $n=1)$; Kampot (2012, $n=1 ; 2015, n=1)$; Kampong Chhnang (2015, $\mathrm{n}=1$ ); Banteay Meanchey $(2015, n=1)$; and

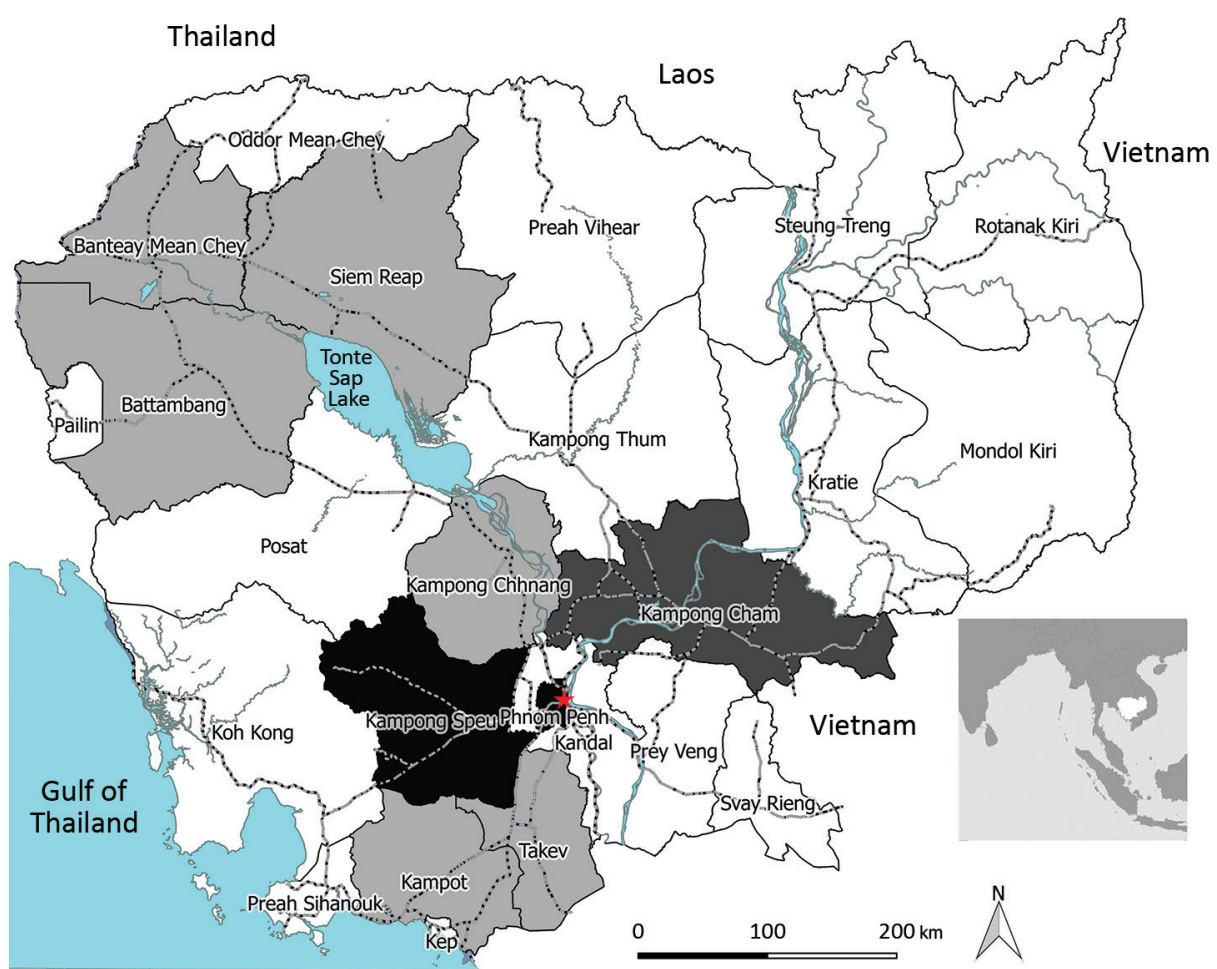
Siem Reap $(2015, \mathrm{n}=4)$ provinces. Light gray indicates provinces with IgM-positive cases, dark gray indicates province with PCR-positive cases, and black indicates provinces with PCR-positive and IgM-positive cases. Inset shows location of Cambodia in Southeast Asia. 
dengue patients and should be completed by a focal entomological study. Moreover, in the absence of a previously detected Zika outbreak in Cambodia, seroprevalence studies in the general population should help estimate the size of the population remaining susceptible to Zika infection.

\section{Acknowledgments}

We thank the participating clinicians and hospitals for patient enrollment and management. We also thank the World Health Organization Collaborating Center for Arboviruses and Viral Hemorrhagic Fever at the Institut Pasteur de Dakar for providing us with a Zika virus strain.

Our study was funded by Institut Pasteur International Network, Actions Concertées Inter-Pasteuriennes (2014/A15) and the European Union Seventh Framework Programme (FP7/2007/2011) under Grant Agreement 282378.

Dr. Duong is the deputy-head of the Virology Unit at the Institut Pasteur du Cambodge. His research interests focus on diagnosis, molecular characterization, and epidemiology of arboviruses and other emerging diseases in tropical regions.

\section{References}

1. Simpson DI. Zika virus infection in man. Trans R Soc Trop Med Hyg. 1964;58:335-8. http://dx.doi.org/10.1016/0035-9203 (64)90201-9

2. Musso D, Gubler DJ. Zika virus. Clin Microbiol Rev. 2016;29:487524. http://dx.doi.org/10.1128/CMR.00072-15

3. Duffy MR, Chen TH, Hancock WT, Powers AM, Kool JL, Lanciotti RS, et al. Zika virus outbreak on Yap Island, Federated States of Micronesia. N Engl J Med. 2009;360:2536-43. http://dx.doi.org/10.1056/NEJMoa0805715

4. Campos GS, Bandeira AC, Sardi SI. Zika virus outbreak, Bahia, Brazil. Emerg Infect Dis. 2015;21:1885-6. http://dx.doi.org/10.3201/eid2110.150847

5. ProMED. Zika virus (44): Singapore, alert, travel advice [cited 2016 Sept 2]. http://www.promedmail.org, archive no. 20160902.4459546
6. Cauchemez S, Besnard M, Bompard P, Dub T,

Guillemette-Artur P, Eyrolle-Guignot D, et al. Association between Zika virus and microcephaly in French Polynesia, 2013-15: a retrospective study. Lancet. 2016;387:2125-32. http://dx.doi.org/10.1016/S0140-6736(16)00651-6

7. Plourde AR, Bloch EM. A literature review of Zika virus. Emerg Infect Dis. 2016;22:1185-92. http://dx.doi.org/10.3201/ eid2207.151990

8. Huy R, Buchy P, Conan A, Ngan C, Ong S, Ali R, et al. National dengue surveillance in Cambodia 1980-2008: epidemiological and virological trends and the impact of vector control. Bull World Health Organ. 2010;88:650-7. http://dx.doi.org/10.2471/BLT.09.073908

9. Heang V, Yasuda CY, Sovann L, Haddow AD, Travassos da Rosa AP, Tesh RB, et al. Zika virus infection, Cambodia, 2010. Emerg Infect Dis. 2012;18:349-51. http://dx.doi.org/10.3201/eid1802.111224

10. Lanciotti RS, Kosoy OL, Laven JJ, Velez JO, Lambert AJ, Johnson AJ, et al. Genetic and serologic properties of Zika virus associated with an epidemic, Yap State, Micronesia, 2007. Emerg Infect Dis. 2008;14:1232-9. http://dx.doi.org/10.3201/ eid1408.080287

11. Balm MND, Lee CK, Lee HK, Chiu L, Koay ESC, Tang JW. A diagnostic polymerase chain reaction assay for Zika virus. J Med Virol. 2012;84:1501-5. http://dx.doi.org/10.1002/jmv.23241

12. Centers for Disease Control and Prevention. Interim guidance for Zika virus testing of urine-United States, 2016. MMWR Morb Mortal Wkly Rep. 2016;65:474. http://dx.doi.org/10.15585/mmwr. $\mathrm{mm} 6518 \mathrm{e} 1$

13. Andries AC, Duong V, Ly S, Cappelle J, Kim KS, Lorn Try P, et al. Value of routine dengue diagnostic tests in urine and saliva specimens. PLoS Negl Trop Dis. 2015;9:e0004100. http://dx.doi.org/10.1371/journal.pntd.0004100

14. Tamura K, Peterson D, Peterson N, Stecher G, Nei M, Kumar S. MEGA5: molecular evolutionary genetics analysis using maximum likelihood, evolutionary distance, and maximum parsimony methods. Mol Biol Evol. 2011;28:2731-9. http://dx.doi.org/ 10.1093/molbev/msr121

15. ProMED. Zika virus (11): Americas, Europe, Asia [cited 2016 Mar 1]. http://www.promedmail.org, archive no. 20160301.4059896.

Address for correspondence: Philippe Dussart, Institut Pasteur du Cambodge, Virology Unit, 5 Monivong Blvd, PO Box 983, Phnom Penh, Cambodia; email: pdussart@pasteur-kh.org

\section{EID Podcast: Musings on Sketches, Artists, and Mosquito Nets}

James Abbott McNeill Whistler was born in Lowell, Massachusetts, on July 11, 1834. When he was 9 years of age, his family moved to St. Petersburg, Russia, and there he studied drawing at the Imperial Academy of Science.

In Man at Table beneath Mosquito Net, Whistler himself might be the subject of this black ink drawing, part of a collection of such drawings from 1854-55. Whistler captures the continued struggle of humans versus biting and stinging insects, including those that transmit vectorborne pathogens, from an intimate perspective.

Despite the mosquitoes teeming around him, the man is able to sketch intently and without worry, sheltered by the confines of his personal impenetrable veil. The flurry of cross-hatched, finely scrawled lines in these ephemera could be seen to mimic a mosquito's flight path but this was simply a common technique that Whistler used in his sketches.

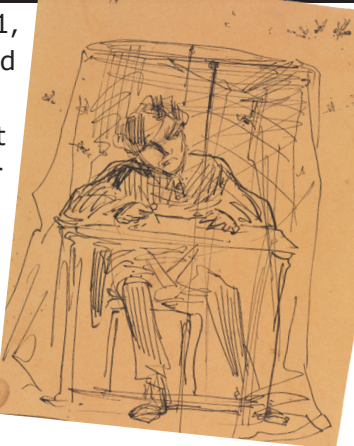

